NUREG/CR-3765

BNL-NUREG-51766

\title{
MINET SIMULATION OF A HELICAL COIL SODIUM/WATER STEAM GENERATOR, INCLUDING STRUCTURAL EFFECTS
}

\author{
Gregory J. Van Tuyle
}

\section{DO NOT MICROFILM \\ COVER}

Date Published - April 1984

CODE DEVELOPMENT, VALIDATION AND APPLICATION GROUP

DEPARTMENT OF NUCLEAR ENERGY, BROOKHAVEN NATIONAL LABORATORY

UPTON, LONG ISLAND, NEW YORK 11973 


\section{DISCLAIMER}

This report was prepared as an account of work sponsored by an agency of the United States Government. Neither the United States Government nor any agency Thereof, nor any of their employees, makes any warranty, express or implied, or assumes any legal liability or responsibility for the accuracy, completeness, or usefulness of any information, apparatus, product, or process disclosed, or represents that its use would not infringe privately owned rights. Reference herein to any specific commercial product, process, or service by trade name, trademark, manufacturer, or otherwise does not necessarily constitute or imply its endorsement, recommendation, or favoring by the United States Government or any agency thereof. The views and opinions of authors expressed herein do not necessarily state or reflect those of the United States Government or any agency thereof. 


\section{DISCLAIMER}

Portions of this document may be illegible in electronic image products. Images are produced from the best available original document. 
This report was prepared as an account of work sponsored by an agency of the United States Government Neither the United States Government nor any agency thereof, nor any of their employees, makes any warranty, express or implied, or assumes any legal liability or responsibility for the accuracy, completeness, or usefulness of any information, apparatus, product, or process disclosed, or represents that its use would not infringe privately owned rights Reference herein to any specific commercial product, process, or service by trade name, trademark, manufacturer, or otherwise does not necessarily constitute or imply its endorsement, recommendation, or favoring by the United States Government or any agency thereof The views and opinions of authors expressed herein do not necessarily state or reflect those of the United States Government or any agency thereof

\title{
MINET SIMULATION OF A HELICAL COIL SODIUM/WATER STEAM GENERATOR, INCLUDING STRUCTURAL EFFECTS
}

\author{
Gregory J. Van Tuyle
}

ITUREG/CR--3765

FI84 016795

\author{
Manuscript Completed — March 1984 \\ Date Published - April 1984
}

\section{CODE DEVELOPMENT, VALIDATION AND APPLICATION GROUP DEPARTMENT OF NUCLEAR ENERGY BROOKHAVEN NATIONAL LABORATORY UPTON, LONG ISLAND, NEW YORK 11973}

PREPARED FOR

U.S. NUCLEAR REGULATORY COMMISSION

WASHINGTON D.C. 20555

UNDER CONTRACT NO. DE-AC02-76CH00016

NRC FIN A-3262 


\section{NOTICE}

This report was prepared as an account of work sponsored by an agency of the United States Government. Neither the United States Government nor any agency thereof, or any of their employees, makes any warranty, expressed or implied, or assumes any legal liability or responsibility for any third party's use, or the results of such use, of any information, apparatus, product or process disclosed in this report, or represents that its use by such third party would not infringe privately owned rights.

The views expressed in this report are not necessarily those of the U.S. Nuclear Regulatory Commission.

\section{Available from} GPO Sales Program

Division of Technical Information and Document Control

U.S. Nuclear Regulatory Commission

Washington, D.C. 20555

and

National Technical Information Service

Springfield, Virginia 22161 


\section{Abstract}

A test transient performed at a helical coil sodium-to-water steam generator test facility was simulated using the MINET code. It was determined that correct calculation of the sodium outlet temperature requires representation of heat capacitance of the structure. 


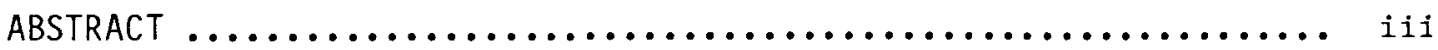

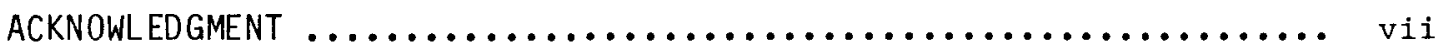

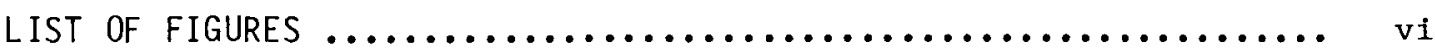

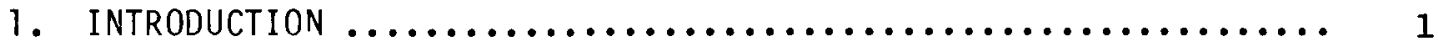

2. MINET $\ldots \ldots \ldots \ldots \ldots \ldots \ldots \ldots \ldots \ldots \ldots \ldots \ldots \ldots \ldots \ldots \ldots \ldots \ldots \ldots \ldots \ldots, 1$

2.1 MOMENTUM INTEGRAL NETWORK METHOD $\ldots \ldots \ldots \ldots \ldots \ldots . . . \ldots$

2.2 COMPONENT MODELS $\ldots \ldots \ldots \ldots \ldots \ldots \ldots \ldots \ldots \ldots \ldots, 4$

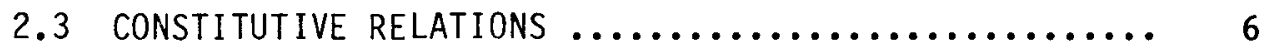

2.4 THE Minet CODE............................. 7

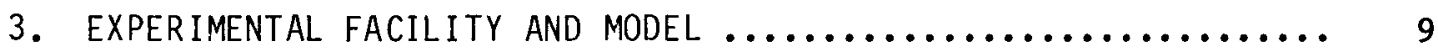

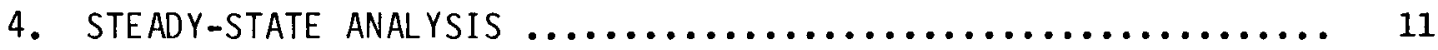

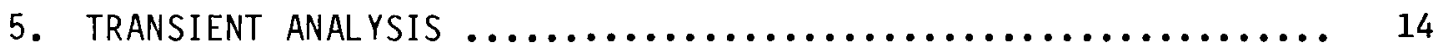

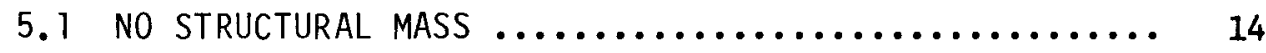

5.2 "EFFECTIVE" STRUCTURAL THICKNESS ASSUMED AT 100\%

5.3 "EFFECTIVE" STRUCTURAL THICKNESS ASSUMED AT 150\% REFERENCE THICKNESS....................... 17

5.4 "EFFECTIVE" STRUCTURAL THICKNESS ASSUMED AT 200\% REFERENCE THICKNESS...................... 17

5.5. INFINITE STRUCTURAL MASS $\ldots \ldots \ldots \ldots \ldots \ldots \ldots \ldots \ldots \ldots \ldots$

6. CONCLUSIONS 17

7. REFERENCES 21 
1 CO-AXIAL HELICAL COIL TUBE $\ldots \ldots \ldots \ldots \ldots \ldots \ldots \ldots \ldots \ldots$

2 CO-AXIAL TUBE, END VIEW $\ldots \ldots \ldots \ldots \ldots \ldots \ldots \ldots \ldots \ldots \ldots$

3 STEADY-STATE TEMPERATURE DISTRIBUTION ............ 12

4 CRITICAL HEAT FLUX (CHF) IN COILED TUBE............ 13

5 TRANSIENT TEMPERATURES WITH NO STRUCTURE ............ 15

6 TRANSIENT TEMPERATURES WITH EFFECTIVE THICKNESS ASSUMED AT $100 \%$ REFERENCE THICKNESS............. 16

7 TRANSIENT TEMPERATURES WITH EFFECTIVE THICKNESS ASSUMED AT $150 \%$ REFERENCE THICKNESS............. 18

8 TRANSIENT TEMPERATURES WITH EFFECTIVE THICKNESS ASSUMED AT $200 \%$ REFERENCE THICKNESS.............. 19 TRANSIENT TFMPERATURES ASSUMING INFINITE STRUCTURE.... 20 


\section{Acknowledgments}

Several people assisted in the preparation of this report. In particular, Mr. Robert Kennett assisted with the computer generated plots, Dr. James Guppy reviewed and edited the text, and Carmen Falkenbach and Kathy Koenig typed and processed the report. Funding for this effort was provided by the Power Reactor and Nuclear Fuel Development Corporation (PNC) of Japan and the U.S. Nuclear Regulatory Commission. 


\section{Introduction}

The MINET (Momentum Integral Network) code [1] heat exchanger model was used to analyze transient test data [2] provided by the Power Reactor and Nuclear Fuel Development Corp. (PNC) of Japan. Testing of the MINET model is part of a larger effort to facilitate and validate the use of the SSC/MINET code [3] for MONJU plant transient analysis. MONJU is a 280-MW(e) powergenerating prototype liquid-metal fast breeder reactor plant (loop-type) that utilizes helical coil heat exchangers between the intermediate loop sodium and the steam qenerator water/steam system.

The same test data has been utilized in a previous study, using an earlier version of the MINET code. In the transient results reported at that time [4], MINET-calculated sodium outlet temperatures changed more quickly than those measured experimentaliy. At that time, the discrepancy was attributed to "an imprecise representation of the boiling boundary", an area that was al ready under revision.

Since the previous analysis, major improvements have been made in the MINET code. The representation of the "boiling" and other heat transfer boundaries was improved. Further, a model was added to account for the heat storage in the structure. The new, improved version was then used to repeat the analysis.

The first finding was that the tendency of MINET calculated temperatures (with no structure) to lead the experimentally determined value was unchanged, despite the improvement in heat transfer boundary representation. A second, and more important finding was that representation of the structural heat capacitance greatly improves the sodium temperatures calculated.

\section{MINET}

MINET (Momentum Integral NETwork) is a computer code developed for the transient analysis of intricate fluid flow and heat transfer networks, such as those found in the balance of plant in power generating facilities. It can be utilized as a stand-alone code, or interfaced to another computer code for 
concurrent analysis. Through such coupling, a computer code currently limited by either the lack of required component models or poor computational speed can be extended to more fully represent the themal hydraulic system, thereby reducing the need for estimating essential transient boundary conditions.

\subsection{The Momentum Integral Network Method}

The method employed in the MINET code is a major extension of a momentum integral method developed by Meyer [5]. Meyer integrated the momentum equation over several linked nodes, called a segment, and used a segment average pressure, evaluated from the pressures at both ends. Nodal mass and energy conservation detemined nodal flows and enthalpies, accounting for fluid compression and thermal expansion.

In MINET, a network structure was built around Meyer's momentum integral model for the flow segment. In this extended method, a system is represented using one or more flow networks, connected to one ancther only through heat exchangers. Each network is composed of segments, volumes and boundaries. Segments contain one or more pipes, pumps, heat exchangers and valves, each of which is represented using one or more nodes. Volumes represent voluminous components and significant flow junctions. Volumes and boundaries are connected by segments.

In systems which can be represented by MINET, heat exchangers are frequently shared by segments in two networks, with the flow from one segment passing through the tubes and the flow from the other passing on the outside. In order to decouple these segments during a transient time step, the tube temperatures are treated explicitly in the heat transfer calculations, and are not advanced until the end of the step.

With the segments and networks thus decoupled, MINET transient calculations proceed in a three step process, repeated for each network. The initial step is to march through the network segments, loading the segment matrix equation

$$
\underline{\underline{A}} \underline{\underline{x}} \underline{s}=\underline{\underline{B}} \underline{\underline{y}} \underline{y}_{s}
$$


and solvinq for the segment response matrix, $\underline{\underline{B}}_{s}^{\prime}\left(=\underline{A_{s}} s^{-1} \underline{\underline{B}} s\right) \cdot$ For a seqment $s$ with $N_{s}$ nodes, $2 N_{S}+2$ linearized equations are loaded, including $\mathrm{N}_{\mathrm{S}}$ nodal mass conservation equations, a segment momentum equation, and a total of $\mathrm{N}_{\mathrm{S}}+1$ donor-cell differenced nodal energy equations and segment inlet enthalpy boundary conditions. Vector $\underline{x}_{s}$ contains nodal interface enthalpies and flows, and vector $\underline{y}_{s}$ includes changes in enthalpy and pressure in the modules at the seqment ends.

The second stage is to march through the network volumes loading the network matrix eauation

$$
\underline{C}_{n} \underline{v}_{n}=\underline{D}_{n}
$$

and solving to advance volume enthalpies and pressures. For a network $n$ with $N_{n}$ volumes $N_{n}$ conservation of mass and $N_{n}$ conservation of energy equations are loaded. The terms for the mass and energy entering and exiting the volumes are evaluated using the segment response matrices, $B_{S}^{\prime}$, thereby linking the volumes.

The final step is to march through the network segments, using the solution from Eq. 2 to determine vector $\underline{y}_{s}$. The segment response matrix, $\underline{B}_{S}^{\prime}$, is then multiplied by $\underline{y}_{s}$, and the nodal interface enthalpies and flows are advanced. After segment conditions are advanced in all networks, the heat exchanger tube temperatures are advanced.

Two features of the method account for the flexibility and speed of MINET. First, seqment nodes connect only to immediately adjacent nodes, causing matrix $\underline{A}_{S}$ to be banded, except for the momentum equation. This allows the storage of matrix $\underline{\underline{A}}_{S}$, and the solution of Eq. 1, in close-packed form, i.e., with larqe blocks of zeroes suppressed. Thus, the complexity of the flow network is absorbed entirely in Eq. 2, where the matrices are lower order. Second, because a segment average pressure is used, saturation properties are evaluated once per segment per step. 


\subsection{Component Models}

While the momentum integral network method forms the basis for the MINET code, several component models, called "modules", are used to determine key parameters in the basic conservation equations. These parameters include the heating term in the energy equation and the pressure loss term in the momentum equation.

Seqment Components

Segment components include pipes, pumps, heat exchangers, valves, and turbine stages. Each representative module contributes pressure "losses" to the seqment momentum equation.

Pipes

Pipes are the simplest component to represent. Pressure losses due to friction, gravity, acceleration, and form (i.e., obstructions) are calculated. Module heating or cooling is user-input as a function of time.

$\underline{\text { Pumps }}$

Pumps are essentially one node pipes with an additional pressure "loss" term due to the pump head. Coefficients for the pump head as a fourth order polynomial fitted function of the pump flow rate, at a reference pump speed, are input by the user. A family of curves is implied for all pump speeds, based on the assumption that the head varies with the square of the pump speed. The pump speed is presently determined in one of three ways: 1) a user-input value vs. time table, 2) a simple coastdown model, or 3) a control system calculation.

Valves

Valves are basically one node pipes, with an additional pressure loss term due to the drop across the valve opening. The user has the option of ignoring the possibility of critical flow at the valve orifice, or using critical flow models by Henry-Fauske or Moody, or an isentropic model for superheat, to place an upper bound on the flow passing through the valve. If critical flow is anticipated, the valve must be isolated in a segment by itself, as the imposition of a local choked flow limit is in conflict with the segment integral momentum equation. The valve position can be: 
1) user-input as a function of time, 2) calculated in response to pressure (safety/relief) or flow (check), or 3) determined by a control system calculation.

Heat Exchangers

Heat exchangers are treated as two pipes linked via heat transfer through the tube wall. The heat transfer from the tube to the fluid is calculated at each time step and used in the nodal energy equations. A fixed mesh nodalization is used, with any change in heat transfer regime within nodes factored into the nodal heat flux calculation, i.e., heat flux is piecewise averaged.

There are several heat exchanger designs in use, particularly if one includes the experimental units, which provide much of the transient data needed for code validation. A number of options are available in MINET, including co- and counter-flow; straight and helical tubes; and co-axial, square, and hex (triangular pitch) tube configurations.

\section{Volumes}

Volumes are computational modules used to represent voluminous system components, as well as locations in a network where pressure must be accurately monitored, e.g., significant flow junctions. For example,one would use one or more volumes (connected by short, wide pipes) to represent a pressurizer or steam drum, or for a header between flow paths of unequal resistance. Currently, one can specify the geometry as a box shape, a vertical or horizontal drum, or a partial box or drum, as well as the operating conditions, i.e., whether the contents are distributed homogeneously or, if saturated, divided into liquid and vapor regions.

Boundaries

External interfaces to the MINET system representation are provided through the boundary modules. At each boundary, two conditions are required: 1) pressure or flow, and 2) temperature, enthalpy, or quality (if saturated). These are supplied by the user or by another computer code. Generally, the temperature parameter will be used in the MINET calculations only when flow is entering the system. The exception to this rule is that the user can fix the temperature at an outlet boundary during the steady state, provided that some heating source is available for ad- 
justment by MINET. MINET will always calculate the unspecified flow/ pressure parameter and the temperature of the flow exiting the system, save for the one exception where the temperature is fixed by the user. With regard to pressure and flow, the user must provide the pressure at outlet boundaries and the flow at inlet boundaries for the steady state calculations. There is no restriction as to which parameter is specified for the transient calculations. The steady state restriction may be relaxed in future versions of MINET.

\section{Turbine Stages}

A turbine stage model has recently, been added to MINET. It is a quasi-static model that is based on known performance, as opposed to geometric detail.

\subsection{Constitutive Relations}

In addition to the basic MINET method and the supporting component models, various constitutive relations are needed for fluid properties and heat transfer. Currently MINET contains properties and correlations for water/ steam, air, sodium, and eutectic Nak.

Because of the complexity introduced by phase changes, the package of functions for water and steam is the most extensive. The property functions are based on polynomial fits of the 1967 ASME steam tables. The heat transfer correlations include those for subcooled convection, subcooled nucleate boiling, forced convection vaporization, film boiling, superheated convection, and filmwise condensation.

Air is treated as an ideal gas, but the property functions are programmed to parallel the functions for water/steam. A heat transfer correlation for air crossing heated tubes is available in MINET, and other correlations can easily be added as they are needed.

Sodium and Nak are assumed to be subcooled, and in that state they are essentially incompressible. Both are treated as thermally expandable, i.e., the density changes with temperature. The property functions are programmed to parallel those for water/steam and air. Heat transfer correlations are available for both fluids, whether passing inside or outside of tubes. In principle, MINET could analyze boiling or superheating in either fluid, once appropriate properties and correlations have been added. 


\subsection{The MINET Code}

The MINET code is relatively small and fast running, due to modular programming, careful data structuring, and an underlying numerical method that allows a large problem to be broken down into several small ones. In addition, steps have been taken to maximize the range of problems that can be analyzed, as well as the potential for concurrent application, i.e., with another computer code.

Data Structure

MINET is variably dimensioned, with nearly all of the principal data residing in a large "container" array. Pointers are defined for each variable, which indicate the position in the container array where the values for the variable are located. The contents of, and pointers for, the container array are carefully preserved throughout the calculations.

Most of the storage space used for calculations is accessed through data abstractions. The data abstraction package consists of functions which manage a container array as well as the accessing of the array, through pointers similar to those used in the principal container. Through the data abstractions, MINET can create storage for a matrix equation, perform the matrix calculations, and de-allocate the storage space, so that it is available for other calculations. Thus, the data abstractions facilitate the efficient use and reuse of storage space, while masking the details of container management from high level MINET subroutines.

Input Processor

The MINET input processor reads in a deck of free-format input records, and temporarily stores the data using data abstractions. It then processes the data, linking the various components into segments and networks. The data is then organized according to computational module number, segment number, and network number, and loaded into the principal container.

Steady State Calculations

At the beginning of the steady state calculations, the system configuration, and component geometries and performance are known, as are the flow rates and temperatures at inlet boundaries and the pressures at outlet boundaries. The temperature at an outlet boundary is also known when it has been 
"fixed" by the user. In addition, the form loss factors for each segment component, the valve positions, the pump speeds, and the initial level in any volume with separated (saturated) contents are all known. The user's estimates of the energy transferred into or across (heat exchangers) components are treated as "known" if possible, but are subject to change if they contradict the boundary conditions. The user's estimates of the initial flows out of the volume ports and the network pressures are used only to initialize the iterative process.

The steady state calculation is a four step iterative process. First, energy transfer rates throughout the system are checked against boundary conditions, and any required changes will be made through energy adjustment factors. Second, the adjusted energy transfer rates will be used to determine segment, volume, and boundary enthalpies in each network. Third, pressure losses will be evaluated for every segment in each network, for current flows and enthalpies. During this step, the heat exchangers must be initialized, with an area correction factor used to resolve any discrepancies between the required energy transfer rate and that indicated by the heat transfer correlations. Fourth, the segment flow rates and volumes and inlet boundary pressures are adjusted. At this point, if all the system enthalpies are not converged (from Step 2), the process is repeated, starting again at the first step.

Any adjustment factors for energy or heat transfer will be printed as part of the steady state calculations. Should any of these factors be significantly different than 1.0, the user is expected to review the input data for incons istencies.

\section{MINET Transient Calculations}

The transient calculations are based on the momentum integral network method described earlier. Adjustment factors determined during the steady state calculations are applied consistently in the transient computations. Transients are driven by changes at the boundaries, via the pump or turbine speeds or valve positions, and through the heat sink term in non-heat exchanger modules. All of these parameters can be controlled through user-input value vs. time tables. Alternately, pumps and turbines can be tripped and coasted down and valves can be tripped open and closed in response to pressure (safety/relief) or flow (check). A compatible generic control system is planned, although not currently available. 
3. Experimental Facility and Model:

Because the helical coil steam generator test facility contains information which is proprietary to PNC, the description provided here is very limited. Thus, we will only provide enough information to facilitate understanding of the work described herein.

The facility is composed of a number of parallel coaxial helical-coil tubes. A side and an end view of one such tube are provided in Figures 1 and 2. Water enters the bottom of the unit, inside the inner of the two flow paths, and is heated until it exits as superheated steam at the top of the unit. Sodium enters the top of the unit and passes along the outside flow path, and exits at the bottom, at a somewhat reduced temperature. There are several thermocouples along the flow paths, particularly in the tube analyzed using MINET. Pressures and mass flow rates are al so closely monitored.

When one considers the structure of the test facility, the region bounded by $D_{3}$ and $D_{4}$ in Figure 2 is of primary importance. As there is reported1y insulation along the outside of the co-axial tubes, heat 1osses to the atmosphere are unlikely to be significant. The tube support structure and instrumentation will impact on the total heat capacitance, creating an effective outer diameter $D_{5}$ (not shown), which should be somewhat larger than $D_{4}$.

The heat transfer area between the outer tube structure and the sodium is simp1y:

$$
A=\pi D_{3} l,
$$

where $\ell$ is length. The structure mass is:

$$
M=\frac{\pi \ell}{4} \rho\left(D_{5}^{2}-D_{3}^{2}\right) \text {, }
$$

where $\rho$ is the material density. Of the parameters in Eqs (1) and (2), the only significant uncertainty is in the value of effective diameter $D_{5}$. 


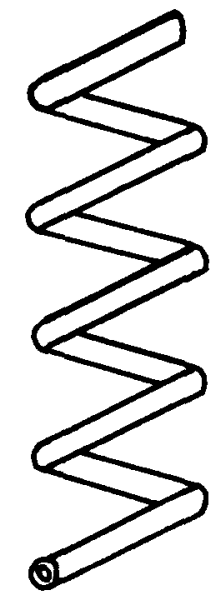

Figure 1. A Co-Axial Helical Coil Tuive

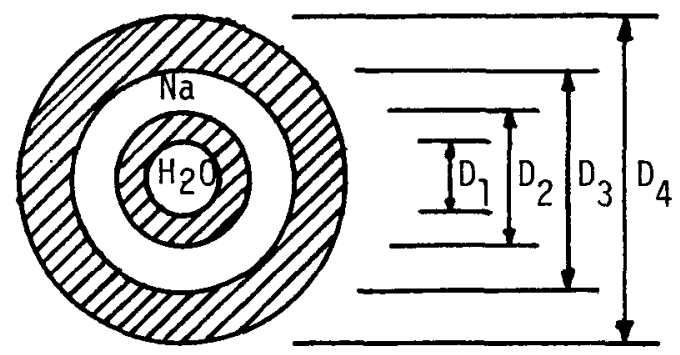

Figures 2. Co-Axial Tubes, End View 
In order to quantify this parameter $D_{5}$, we identify a reference thickness, $t_{j}$, such that

$$
t_{i}=D_{2}-D_{1}
$$

i.e., the thickness of the tube between the water/steam and the sodium. Against this, we will compare the thickness of the effective outer structural region, $t$, defined as:

$$
t=D_{5}-D_{3}
$$

In the analysis to follow, five cases will be considered, using assumed values for $t$ of: $0, t_{j}, 1.5 t_{j}, 2.0 t_{i}$, and $10^{5} \cdot t_{j}$ (i.e.,infinite).

4. Steady State Analysis:

Geometric details and initial conditions for a $70 \% 1$ oad test, including the two mass flow rates, two pressures, and the inlet and outlet temperatues for both sides, were input to MINET. MINET calculated the ititial temperatures and pressures throughout. Using the standard package of MINET heat transfer correlations, a $1 \%$ adjustment in heat transfer area had to be made to match the measured conditions. (Note: Up to a 10\% adjustment is considered to be reasonable.) Nineteen axial nodes were used in representing the heat exchanger.

The calculated and measured temperature distributions are shown in Figure 3. The error in the two phase region, where MINET is calculating a significantiy higher sodium temperature, is attributed to the smearing of the critical heat flux (CHF) region due to the slant of the helical coil. This can be illustrated using Figure 4, which shows CHF in a slanting helical coil tube. Such slanting leads to a gradual CHF, and increasingly more of the heat transfer area is dried out as one passes along to the right. Instead of a gradual transition, MINET assumes a sharp transition, causing an overprediction of the heat transfer rate before CHF and an underprediction after. 


\section{HELICAL COIL HEAT EXCHANGER TEMPERATURES}

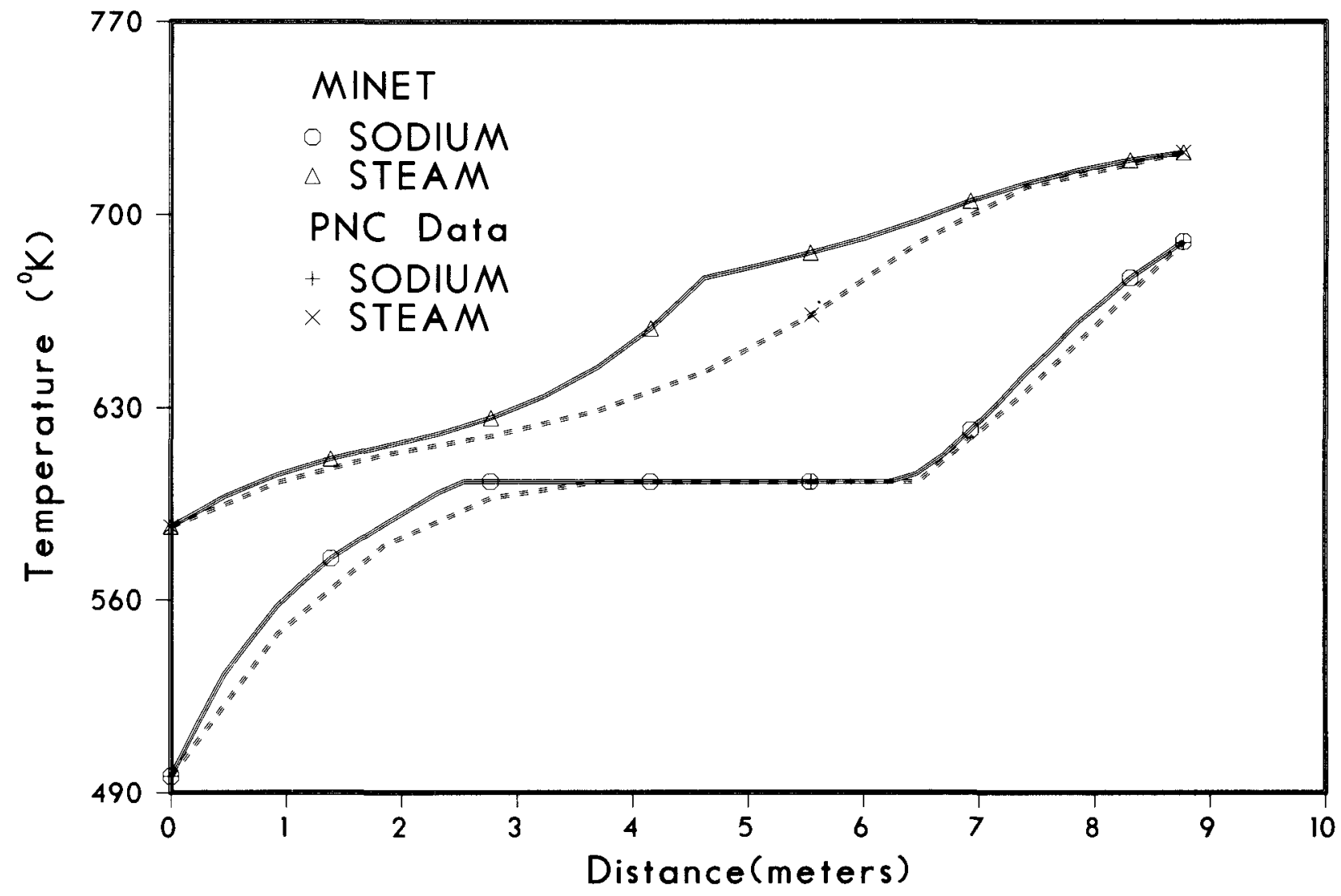

Figure 3. Steady-State Temperature Distribution 


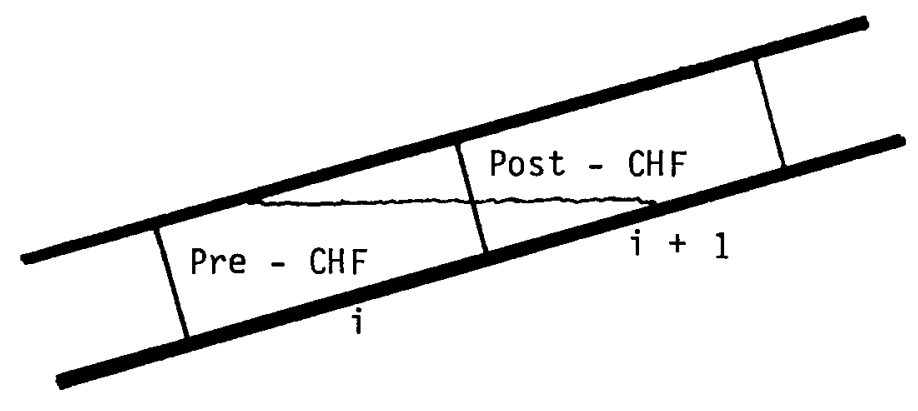

Figure 4. Critical Heat Flux (CHF) In Coiled Tube

$-13-$ 
If one were designing a model purely for this type of heat exchanger, rather that a generalized model for a system's code, one could well pursue a better representation of the behavior illustrated in Figure 4. However, such an effort is not currently planned for MINET, as long as an adequate prediction of the inlet and outlet temperatures of the unit under transient conditions can be obtained.

5. Transient Analysis:

The transient simulated was a $20 \%$ step reduction in feedwater mass flow rate after a $25 \mathrm{~s}$ null transient. Steam outlet pressure, which decreases in response to the reduced feedwater flow, was input as a transient boundary condition. Feedwater temperature, sodium inlet mass flow rate and temperature, and sodium outlet pressure were held constant. Temperatures at the heat exchanger inlets and outlets, as observed and calculated, are shown in Figures 5-9. Approximately 200 seconds of CDC 7600 CPU time were used to simulate each of the 500 second transients.

\subsection{No Structural Mass:}

The case with no structural mass was re-run with the current version of MINET, using the improved representation of the boundaries between heat transfer regimes. The results are shown in Figures 5 , and almost exactly duplicate the results obtained with the older version of MINET and reported in Reference 4. As can be seen, the code does very well in predicting the steam outlet temperature, but calculates the increase in the sodium outlet temperature as developing more quickly than was measured experimentally.

\section{2 "Effective" Structural Thickness Assumed at 100\% Reference Thickness:}

The temperature response for a case with structure as thick as the tube between the water/steam and sodium, is shown in Figure 6 . Note that the tendency for MINET calculated sodium outlet temperatures to lead the measured values has been significantly reduced. This is because the structure temperature starts out the same as the adjacent sodium, and as the sodium heats up, it gives off heat to the structure, so as to raise the structure temperature as well. Thus, it takes more time for the sodium temperature to increase to the new equilibium value. 


\section{HELICAL COIL HEAT EXCHANGER TEMPERATURES}

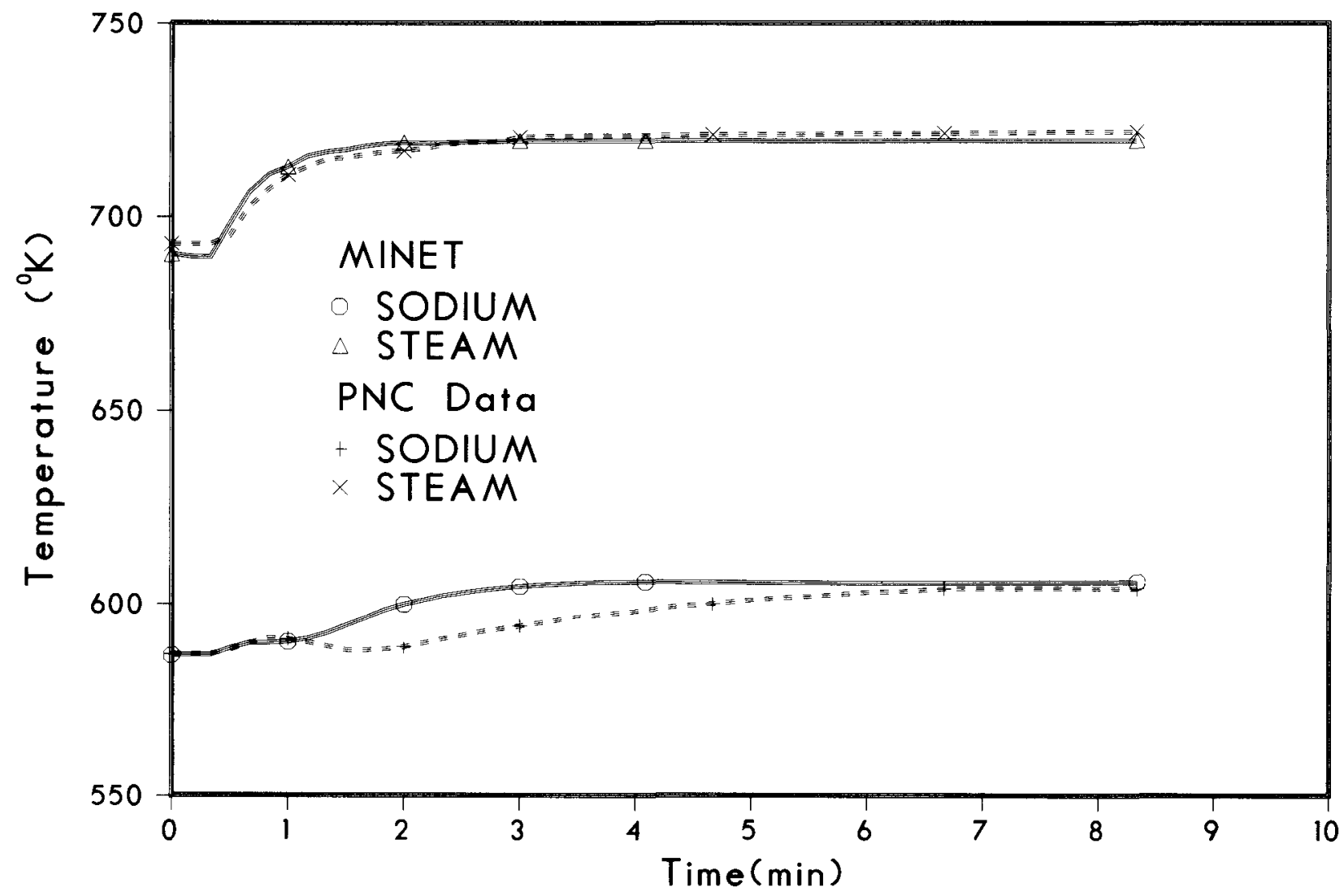

Figure 5. Transient Temperatures with No Structure 


\section{HELICAL COIL \\ HEAT EXCHANGER TEMPERATURES}

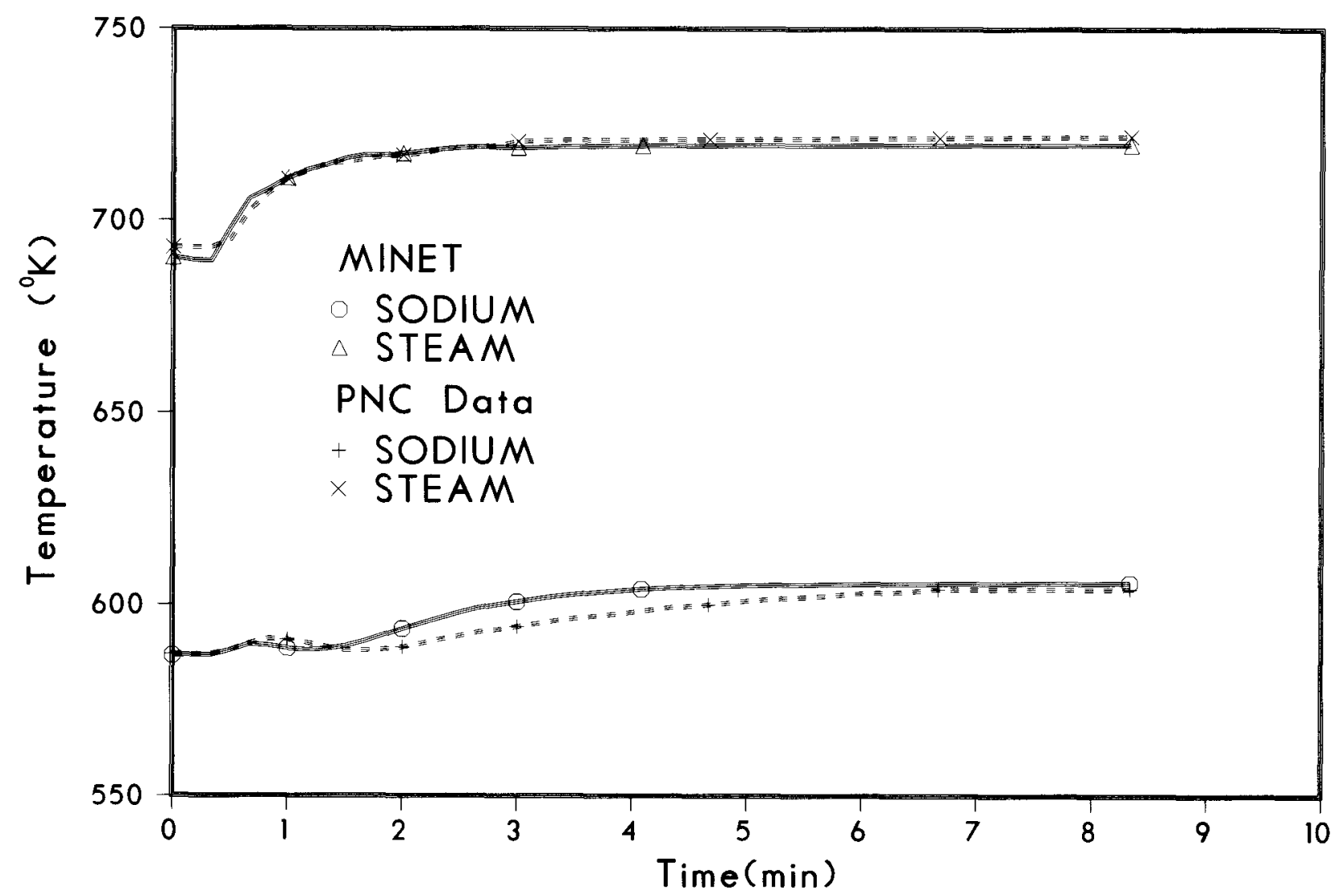

Figure 6. Transient Temperatures with "Effective"

Thickness Assumed at 100\% Reference Thickness 


\section{3 "Effective" Structural Thickness Assumed at 150\% Reference Thickness}

The transient response when the structural thickness assumed to be 1.5 times the inner tube thickness is given in Figure 7. As can be seen, the sodium outlet temperature response has been slowed significantly, and is approaching the experimentally determined response.

\section{4 "Effective" Structural Thickness Assumed at 200\% Reference Thickness}

The transient response when the structure is assumed to be twice as thick as the inner tube thickness is shown in Figure 8 . With this amount of structure, the MINET calculated temperatures nearly match those measured experimentally. In fact, judging by the calculated response and our knowledge of the facility, it seems very likely that this estimate of the structural mass is close to the actual value.

\subsection{Infinite Structural Mass:}

If one carries the structure argument to the extreme, and utilizes an essentially infinite mass, the response is as shown in Figure 9. With infinite structural mass, the sodium temperatures are virtually unchanged, at least for 500 seconds. Further, the steam outlet temperatures no longer change as much because the sodium temperature near the steam outlet is holding constant rather than increasing somewhat, as it was before. Clearly one can not realistically assume infinite structural mass and obtain realistic results.

\section{Conclusions:}

At this point it becomes obvious that the principal reason for the previously noted error in MINET-predicted sodium outlet temperature was the failure to account for the structure that forms the outer boundary for the sodium flow path. Further, it appears that the effective thickness of the structural region, which includes such materials as support structure and instrumentation, is about twice as thick as the inner tube thickness.

The original MINET heat exchanger model did not allow representation of such structure, as larger multi-tube units were envisioned for representation. For these heat exchangers, with larger numbers of tubes and proportionately less structure per tube, one can often obtain a reasonably good prediction without representing the structure. 


\section{HELICAL COIL HEAT EXCHANGER TEMPERATURES}

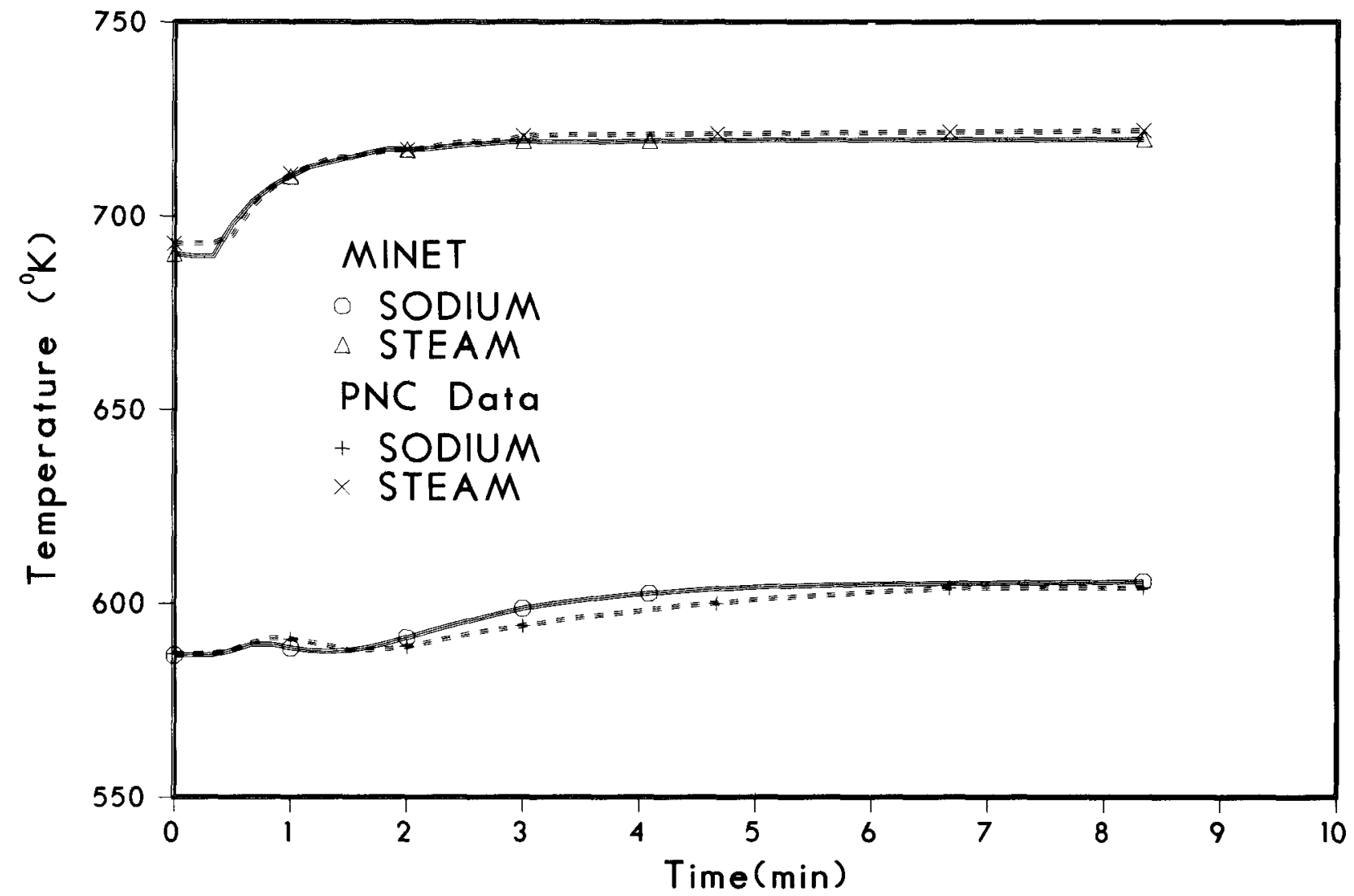

Figure 7. Transient Temperature With "Effective" Thickness Assumed at 150\% Reference Thickness 


\section{HELICAL COIL HEAT EXCHANGER TEMPERATURES}

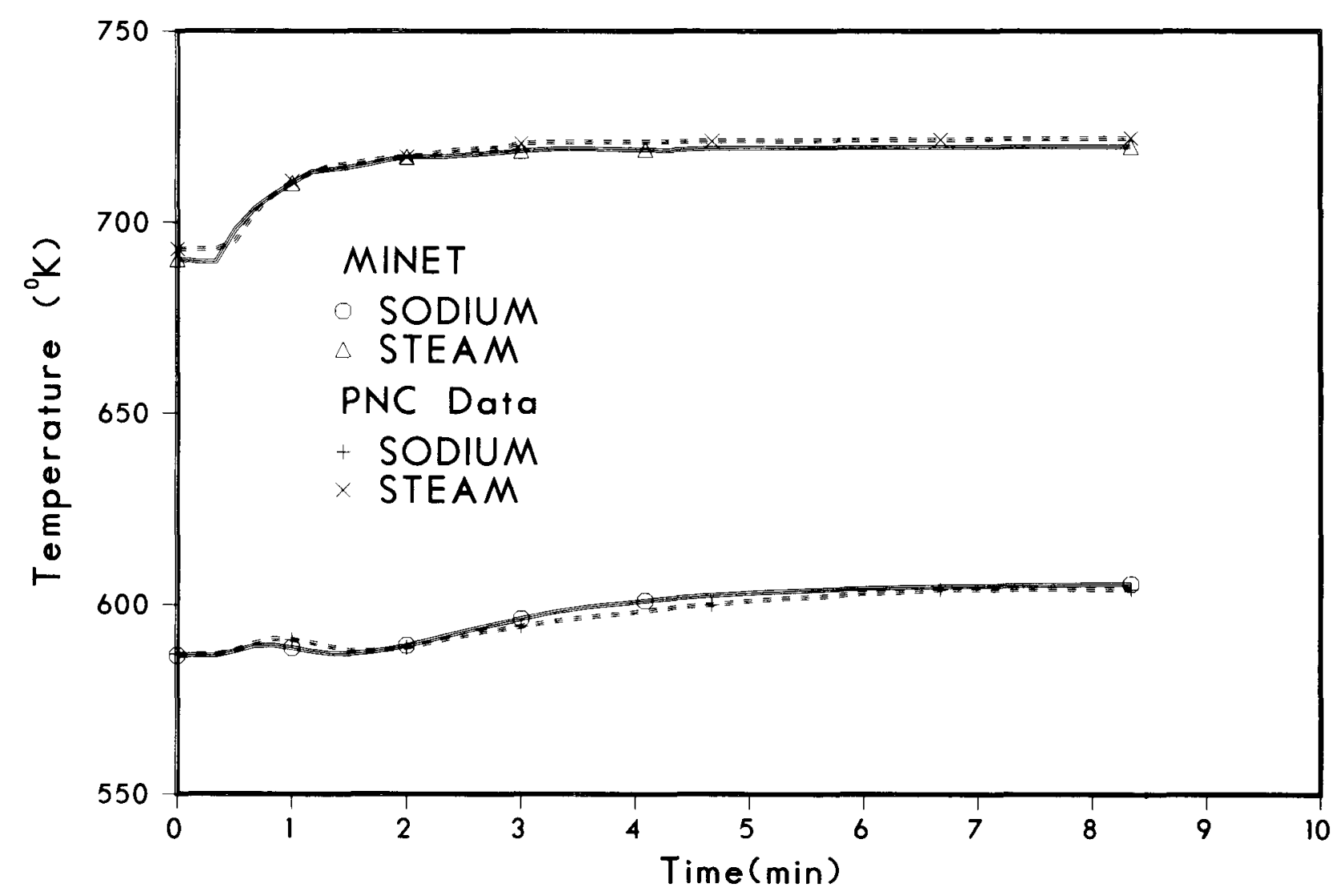

Figure 8. Transient Temperatures with "Effective"

Thickness Assumed at 200\% Reference Thickness 


\section{HELICAL COIL \\ HEAT EXCHANGER TEMPERATURES}

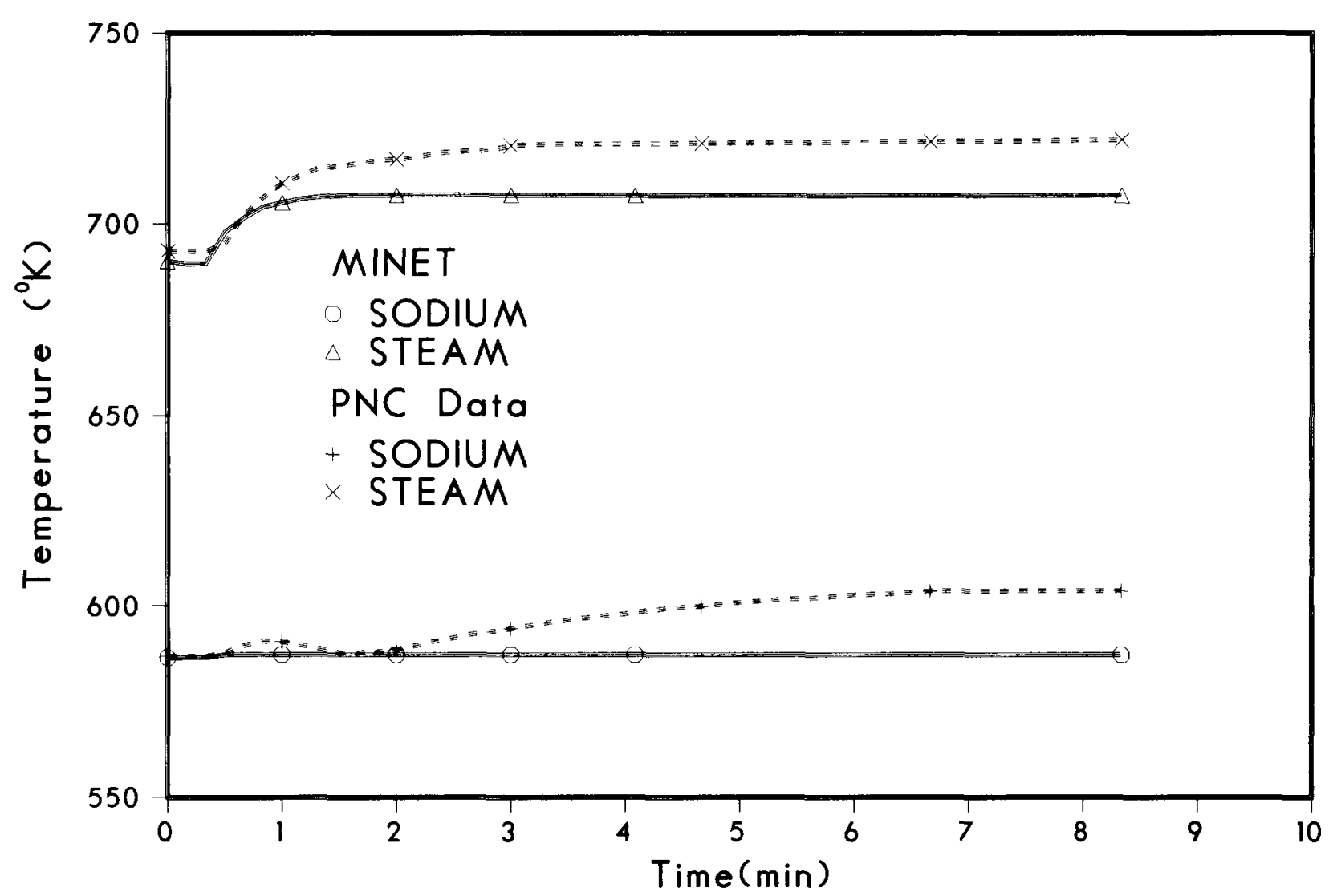

Figure 9. Transient Temperatures Assuming Infinite Structure 
A second interesting point is that one can predict the transient response of the exit temperatures while a significant error remains in calculated temperatures near the critical heat flux location. This may be due to the tendency of errors below and above the CHF location to cancel out.

In conclusion, compensation for the effect of structural mass reduces, and perhaps even eliminates, any significant differences between the MINET predicted temperature response and the experimentally determined one, at least at the component boundaries. As this is the principal goal in respresenting a heat exchanger as part of a system-wide representation, this study supports the use of MINET in the planned SSC/MINET simulation of the MONJU facility.

\section{References:}

1. G. J. Van Tuyle, T. C. Nepsee, J. G. Guppy, "MINET Code Documentation," Brookhaven National Laboratory Report BNL-NUREG-51742, NUREG/CR-3668, February 1984.

2. A. Izume and J. Kubota, "Verification of a Dynamics Model of a Sodium Heated Steam Generator", Boiler Dynamics and Control in Nuclear Power Stations, British Nuclear Energy Society, London (1979).

3. J. G. Guppy, et al., "Super System Code (SSC, Rev.),. An Advanced Thermohydraulic Simulation Code for Transients in LMFBRs", Brookhaven National Laboratory, NUREG/CR-3169, BNL-NUREG-51650, Apri1 1983.

4. G. J. Van Tuyle, T. Iwashita, "Transient Simulation of a Helical Coil Sodium/Water Steam Generator", ANS Transaction, Vol. 43, pg. 569, November 1982.

5. J. E. Meyer, "Hydrodynamic Models for the Treatment of Reactor Thermal Transients", Nuc7. Sci. Eng. 10, 269, 1961. 


\begin{tabular}{|c|c|c|c|}
\hline \multicolumn{2}{|c|}{$\begin{array}{l}\text { NRC FORM } 335 \\
\text { U.S. NUCLEAR REGULATORY COMMISSION } \\
\text { BIBLIOGRAPHIC DATA SHEET }\end{array}$} & \multicolumn{2}{|c|}{1 REPORT NUMEER IAssigneo oY OOCI } \\
\hline \multicolumn{2}{|c|}{4 TITLE ANU SUUTITLE (AdA Volume No., "f eopropriasel } & \multicolumn{2}{|l|}{ 2. (Ledve olonk) } \\
\hline \multicolumn{2}{|c|}{$\begin{array}{l}\text { MINET Simulation of a Helical Coil Sodium/Water Steam } \\
\text { Generator, Including Structural Effects }\end{array}$} & \multicolumn{2}{|c|}{ 3. RECIPIENT'S ACCESSION NO. } \\
\hline \multicolumn{2}{|l|}{ I AUTHOH(S) } & \multicolumn{2}{|c|}{ 5. DATE REPORT COMPLETED } \\
\hline G. J. Van Tuyle & & \multicolumn{2}{|c|}{\begin{tabular}{|l|l} 
MONTH March & YYAAR 1984 \\
\end{tabular}} \\
\hline \multirow{3}{*}{\multicolumn{2}{|c|}{$\begin{array}{l}\text { 9. PEHOHMING OHGANILATION NAME AND MAILING ADDRESS IInclude Zio Codel } \\
\text { Department of NuClear Energy } \\
\text { Brookhaven National Laboratory } \\
\text { Upton, Long Island, New York } 11973\end{array}$}} & \multicolumn{2}{|c|}{\begin{tabular}{|l|l|}
\multicolumn{2}{|c|}{ DATE REPOAT ISSUED } \\
MONTH
\end{tabular}} \\
\hline & & \multicolumn{2}{|l|}{6 (Leave oremk) } \\
\hline & & \multicolumn{2}{|l|}{ 8. (Leave brenk) } \\
\hline \multirow{2}{*}{\multicolumn{2}{|c|}{$\begin{array}{l}12 \text { SPONSORING ORGANIZATION NAME AND MAILING ADDRESS Inelude Zio Code) } \\
\text { Division of ACCident Evaluation } \\
\text { Office of Nuclear Regulatory Research } \\
\text { U.S. Nuclear Regulatory Commission } \\
\text { Washington, D.C. } 20555\end{array}$}} & \multicolumn{2}{|c|}{ 10. PROJECT/TASK/WORK UNIT NO } \\
\hline & & \multicolumn{2}{|c|}{ "A-3262 } \\
\hline \multicolumn{4}{|c|}{$\begin{array}{l}\text { is TYPE OF HEPOHT } \\
\text { Technical Report }\end{array}$} \\
\hline \multicolumn{2}{|l|}{ 13. SUPPLEMEN RAHY NOTES } & \multicolumn{2}{|l|}{14 (Leeve dank) } \\
\hline \multicolumn{4}{|c|}{$\begin{array}{l}16 \text { ABSTRACT } 1200 \text { worrs ar lessl } \\
\text { A test transient performed at a helical coil sodium-to-water steam generator } \\
\text { test facility was simulated using the MINET code. It was determined that correct } \\
\text { calculation of the sodium outlet temperature requires representation of heat } \\
\text { capacitance of the structure. }\end{array}$} \\
\hline \multicolumn{4}{|c|}{$\begin{array}{l}17 \text { KEY WOHUS ANO DOCUMENT ANALYSIS } \\
\text { Heat EXchangers, Steam Generator, Helical Coil, } \\
\text { Thermal Hydraulic Transient Analysis, } \\
\text { Breeder Reactor Plant, } \\
\text { Computer Simulation }\end{array}$} \\
\hline \multicolumn{4}{|c|}{ T/, IOENTIFIE HS OPFN ENDED SERMS } \\
\hline \multirow{2}{*}{$\begin{array}{r}\text { I8 AVAILABILITY STATEMENT } \\
\text { UNLIMITED }\end{array}$} & $\begin{array}{r}19 \text { SECL } \\
\text { unC }\end{array}$ & $\begin{array}{l}\text { ClASS ITnis mooml } \\
\text { ified }\end{array}$ & 21 NO OF PAGES \\
\hline & $\begin{aligned} 20 \mathrm{SECL} \\
\text { und }\end{aligned}$ & $\begin{array}{l}\text { Class linn wove' } \\
\text { Sified }\end{array}$ & 22 PAICE \\
\hline
\end{tabular}

